\title{
Nursing students serve and learn how to check, change, and control blood pressure in the local community
}

\author{
Eyad Musallam*1, Amanda N Changet $^{2}$ \\ ${ }^{1}$ Department of Nursing, Miami University, United States \\ ${ }^{2}$ American Heart Association, United States
}

Received: May 23, 2019

DOI: $10.5430 /$ ijh.v5n2p62
Accepted: July 24, 2019

URL: https://doi.org/10.5430/ijh.v5n2p62
Online Published: August 9, 2019

\begin{abstract}
Background: High blood pressure is currently affecting 103 million people in the United States and is a major risk factor for cardiovascular disease, stroke, and heart failure. The American Heart Association (AHA) launched Check. Change. Control. Program (CCC program). The program is an evidence-based hypertension management program that utilizes blood pressure self-monitoring to empower patients/participants to take ownership of their cardiovascular health.

Project: Following the Partnership Model for Service Learning, Miami University and The AHA propose implementing the "Serve and Learn How to Check, Change, and Control: A Community-Based Intervention to Improve Blood Pressure Control" to improve the BP of a diverse group of residents in Middletown and Hamilton cities in Ohio.

Participants: Fifteen nursing students served as volunteer health mentors. Each nursing student recruited five community members over the age of 18 and checked their blood pressure two times every month for four months. 80 community membered were recruited and joined the project for four months.

Results: At the end of the program, more than half of the participants $(n=41)$ had blood pressure improvement (decrease in systolic or/a diastolic). On third of Tier 1/ HYPERTENSION participants $(n=10)$ have moved from uncontrolled $(>$ or $=$ to $130 / 80$ ) to controlled ( $<$ or $=$ to 129/79) based on comparing the participants' 1st blood pressure reading to their last.

Conclusions: The extremely positive effects of this project are an eye-opening on the need of applying the program on a larger scale. To apply this program on a larger scale, partnerships with community organizations such as community health and wellness centers are needed. These partnerships will provide quality access to healthcare. The students will be able to meet participants where they are in their communities in a safe, vibrant, open and welcoming centers.
\end{abstract}

Key Words: Hypertension, Nursing, Community health, American Heart Association, Service learning

\section{BACKGROUND}

Based on the latest blood pressure guideline released by the American Heart Association's (AHA) nearly half (46\%) of adult Americans have high blood pressure. ${ }^{[1]}$ High blood pressure is currently affecting 103 million people in the United States and is a major risk factor for cardiovascular disease, stroke, and heart failure. ${ }^{[2]}$ Cardiovascular diseases, which includes coronary heart diseases, myocardial infarction, and heart failure, is the leading cause of death in Butler County, Ohio, and the nation. In Butler County according to the data 2011-2015, the mortality rate from heart disease was $166 / 100,000$, and the Ohio state rate was $188.4 / 100,000$. In addition, cerebrovascular disease death most frequently results from a stroke. According to 2015, ODH Ohio Public

*Correspondence: Eyad Musallam; Email: musalle@miamioh.edu; Address: Department of Nursing, Miami University, United States. 
Health Data Warehouse, in Butler County, the mortality rate was 38.7/100,000 and in Ohio State, the mortality rate was 40/100,000. High blood pressure is the main factor associated with both Heart disease and cerebrovascular disease. ${ }^{[3]}$

Community-based non-pharmacological and health education programs may be helpful in improving health outcomes in patients with chronic illnesses. ${ }^{[4,5]}$ Community-based interventions such as health education and counseling found to be effective when compared with alternatives such as wellness visits or primary care follow up. Also, they are cost-effective for certain health conditions, particularly when partnering with low-income, underserved, and racial and ethnic minority communities. ${ }^{[4,5]}$ Several studies evaluate the impact of the community-based interventions and health education programs in controlling high blood pressure. ${ }^{[5-10]}$ Yet many of these programs required significant resources, and their sustainability, and generalizability to other settings was unclear.

The American Heart Association AHA / American Stroke Association (ASA) mission is to build healthier lives free of cardiovascular disease and stroke. ${ }^{[1]}$ In supporting this mission, the AHA launched Check. Change. Control. Program (CCC program). The program is an evidence-based hypertension management program that utilizes blood pressure self-monitoring to empower patients/participants to take ownership of their cardiovascular health. ${ }^{[11]}$ The purpose of the CCC program is to control high blood pressure as a health disparity among Americans and to create a culture of health throughout the communities. CCC program will help in screening and controlling high blood pressure through enhancing blood pressure self-monitoring and empowering participants to take ownership of their cardiovascular health. The program launched as a pilot in August 2012 with a focus on top 18 markets nationwide. As of June 2017, the program has expanded to over 150 markets, 389,000+ participants enrolled with an average drop in systolic blood pressure of $11 \mathrm{mmHg}$. Controlling high blood pressure is considered an important factor in managing both Heart disease and cerebrovascular disease and in lowering the mortality rate. ${ }^{[11]}$

Few studies evaluate the impact of AHA CCC program. ${ }^{[12,13]}$ The result of these studies showed that $\mathrm{CCC}$ as a simplified and cost-effective community-based hypertension intervention programs may lead to BP improvements. One study showed that $\mathrm{CCC}$ demonstrated significant $\mathrm{BP}$ reduction among 2,000 participants from eight Durham, NC outpatient clinics over a 6-month period. ${ }^{[12]}$ In another study 4,069 adults were enrolled into the CCC program at 18 US sites and the results showed that CCC program was associated with improved $\mathrm{BP}$ control $(13.7 \mathrm{mmHg}$ average reduction in

Published by Sciedu Press
$\mathrm{BP})$ in a diverse community-based population. ${ }^{[14]}$

Check. Change. Control is designed to establish community partnerships and meaningful volunteer roles and is focused on innovation and sustainability. The most common program implementation sites were churches, healthcare institutions, community or recreation centers (including YMCAs), worksite wellness programs (e.g., insurance companies), other businesses (e.g., pharmacies, insurance companies), or other (e.g., private societies or organizations, apartment complexes). These sites trained volunteer health mentors to carry out $\mathrm{CCC}$ programs and interact with program participants; these volunteer health mentors were from both healthcare and nonhealthcare backgrounds. ${ }^{[11,14]}$

The literature showed that community health promotion and disease prevention interventions conducted by nursing students have positive impact on the local communities. ${ }^{[15,16]}$ These interventions also can serve as an effective strategy for teaching nursing student competencies and facilitating engagement with the community. ${ }^{[15,16]}$ To engage nursing students in improving local community health outcomes, Miami University partnered with AHA to apply the CCC in the local community. The nursing students at Miami University served as volunteer health mentors and implemented the CCC program in the local community. Following the Partnership Model for Service Learning, ${ }^{[17]}$ Miami University and The AHA propose implementing the "Serve and Learn How to Check, Change, and Control: A Community-Based Intervention to Improve Blood Pressure Control" to improve the BP of a diverse group of residents in Middletown and Hamilton cities in Ohio.

\section{THEORETICAL MODEL}

The Partnership Model for Service-Learning will be utilized to guide the application of the proposed intervention "Serve and Learn How to Check, Change, and Control: A Community-Based Intervention to Improve Blood Pressure Control". The Partnership Model provides a framework to ensure a cohesive plan for teaching, scholarship, and service. ${ }^{[17]}$ A committed "community partner": American Heart Association and the "faculty": Miami University serve as the center of the Partnership Model itself. On a parallel plane to the faculty and community partner, are the students. They are the "driving force" behind the work that is accomplished. The students served as volunteer health mentors and implemented the CCC program in the local community. They provided a constant free flow of service. Another essential component of the Partnership Model involves the target population: a diverse group of residents in Middletown and Hamilton cities in Ohio (see Figure 1). 
The Partnership Model for Service-Learning was successful in guiding and implementing comparable projects. ${ }^{[17]}$ The results of comparable programs showed positive outcomes for faculty members, students, community partners and community members. The model helped the programs in planning and in setting expectations and responsibilities. ${ }^{[17,18]}$

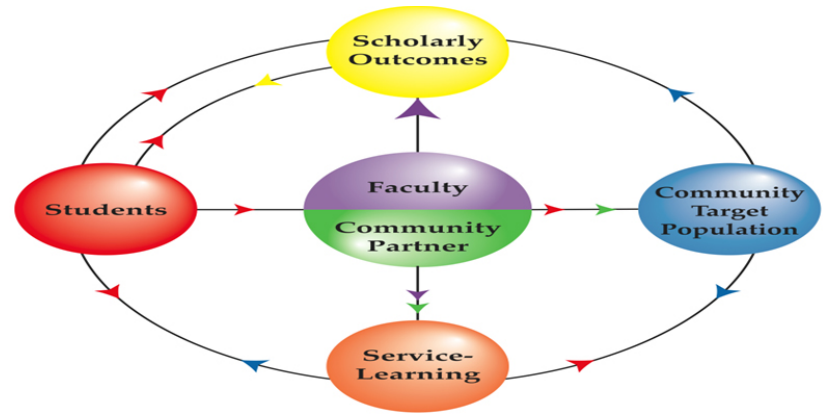

Figure 1. The partnership model for service-learning

\section{Project description}

This is the first time that the AHA CCC program was implemented by nursing students. Integrating the $\mathrm{CCC}$ program in the nursing curriculum will take the AHA CCC program to the next level where nursing students, who have the clinical knowledge and training, implement the blood pressure measurements and provide health education. In the Serve and Learn How to Check, Change, and Control: A Community-Based Intervention, the Nursing department at Miami University integrated the AHA CCC program in the nursing curriculum as a service learning program. The nursing students served as Volunteer Health Mentors. Each nursing student recruited five community members over the age of 18 and checked their blood pressure two times every month for four months. In addition, the students used the AHA CCC program education resources to provide health education about blood pressure. The students utilized the AHA CCC 4 Month HBP Educational Series and offered
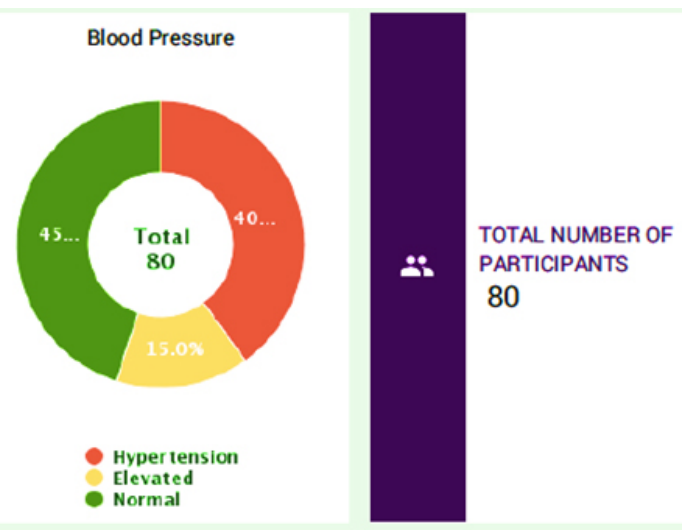

one on one teaching sessions for the participants. ${ }^{[19]}$ The students communicated directly with participants (community members) facilitating their success in the program including successfully uploading blood pressure readings, using an online tracker and strengthening their commitment to the program.

Fifteen nursing students served as Volunteer Health Mentors. Each nursing student recruited five community members over the age of 18 and checked their blood pressure two times every month for four months. 80 community membered were recruited and joined the project for four months. The nursing students recruited their family members, friends, or coworkers. To maximize the benefits for the community members, the students were encouraged to recruit community members who have hypertension.

\section{RESULTS}

From July 1, 2017 to June 30, 2018, a total of 80 participants were enrolled. Participants were stratified into 3 tiers according to their initial BP: Tier 1 / HYPERTENSION (a systolic reading $\geq 130.0 \mathrm{mmHg}$ AND/OR a diastolic reading $\geq 80.0 \mathrm{mmHg})=32$ (40\% of the Participants), tier $2 /$ ELEVATED (systolic reading between 120.0-129.0 mmHg AND a diastolic reading of less than $80.0 \mathrm{mmHg})=12(15 \%$ of the Participants) and tier 3 / NORMAL (a systolic reading $<120.0 \mathrm{mmHg}$ AND a diastolic reading $<80.0 \mathrm{mmHg}$ ) (see Figure 2).

At the end of the program, more than half of the participants $(n=41)$ had blood pressure improvement (decrease in systolic or/a diastolic). On average, $9.8 \mathrm{mmHg}$ decrease in systolic blood pressure and $7.9 \mathrm{mmHg}$ decrease in diastolic blood pressure. On third of Tier 1/ HYPERTENSION participants $(n=10)$ have moved from uncontrolled $(>$ or $=$ to $130 / 80$ ) to controlled ( $<$ or $=$ to $129 / 79$ ) based on comparing the participants' 1 st blood pressure reading to their last (see Figure 3).

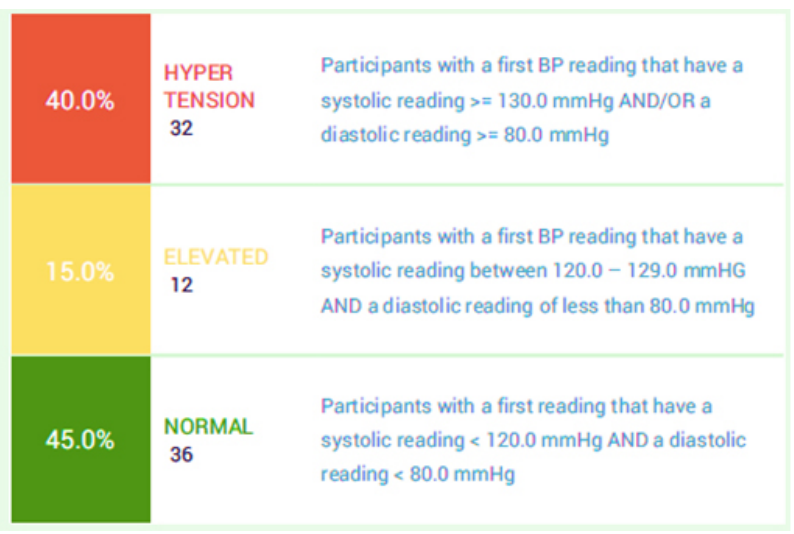

Figure 2. Blood pressure tiers 


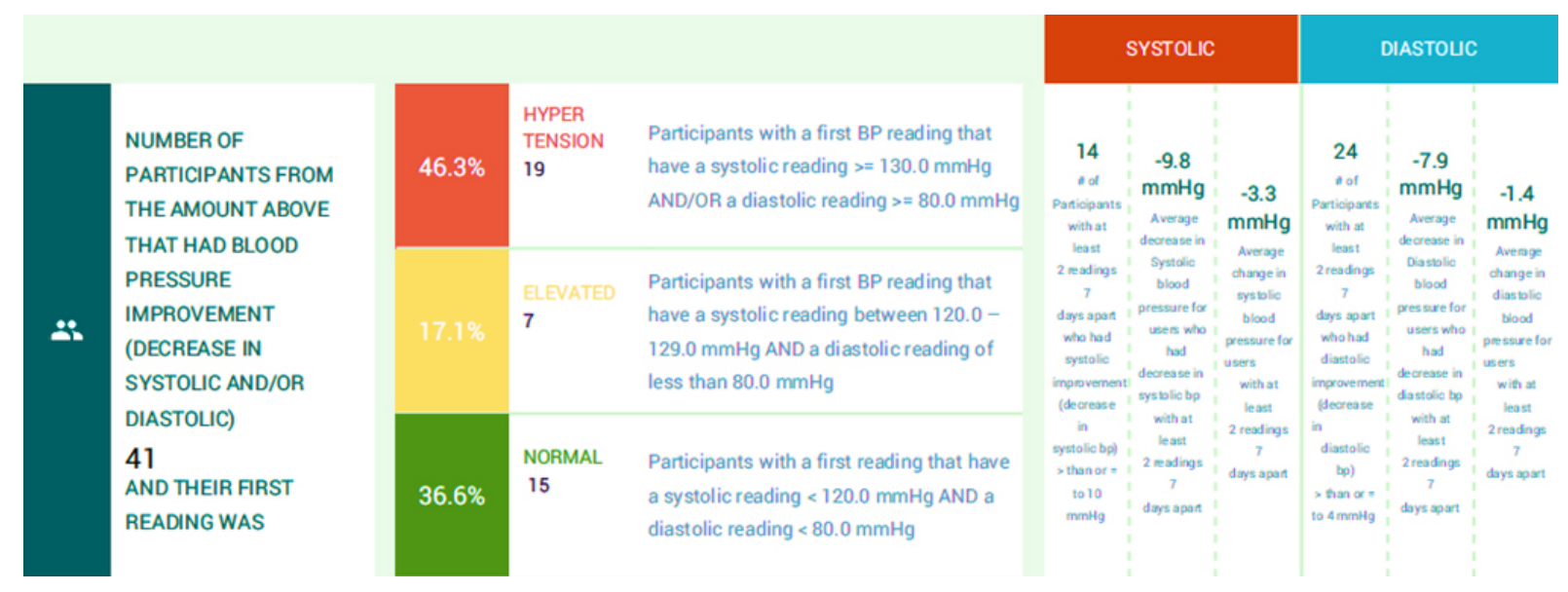

Figure 3. Changes in blood pressure readings

\section{DiscusSion}

High blood pressure is currently affecting 103 million people in the United States. Hypertension or High blood pressure is a major modifiable risk factor for cardiovascular disease, stroke, and heart failure. Community-based programs that help in improving high blood pressure screening and selfcare management are needed. Several prior studies have demonstrated that the use of screening, health education and self-monitoring can promote improved hypertension control. ${ }^{[5,7-10,14]}$

In 2013, The AHA launched CCC program as an evidencebased hypertension management program that utilizes blood pressure self-monitoring to empower patients/participants to take ownership of their cardiovascular health. The CCC programs depends on volunteer health mentors to carry out the programs and interact with program participants; these volunteer health mentors were from both healthcare and nonhealthcare backgrounds. This is the first time that the AHA CCC program was implemented by nursing students. Integrating the CCC program in the nursing curriculum will take the AHA CCC program to the next level where nursing students, who have the clinical knowledge and training, implement the blood pressure measurements and provide health education.

The result of this study showed the effectiveness of CCC program in improving the participants' blood pressure and blood pressure self-monitoring. In addition, the program was a great opportunity for the nursing students to practice clinical activities addressing community and population health. The positive results of this study support the findings of previous studies that investigated the CCC program. ${ }^{[12,13]}$

The extremely positive effects of this project are an eyeopening on the need of applying the program on a larger scale and invite other nursing programs in the region and US to participate in CCC program. To apply this program on a larger scale, partnerships with community organizations such as community health and wellness centers are needed. These partnerships will provide quality access to healthcare. The students will be able to meet participants where they are in their communities in a safe, vibrant, open and welcoming centers.

\section{Conclusions}

Implementing Check Change Control by nursing students was a novel community-based initiative that demonstrated reduction in BP among a sample from two local communities. Future efforts could focus on adopting this initiative by other nursing programs in the region to cover more underserved communities. We have learned that partnerships with other community organizations (such as YMCA) might enhance the participation in the CCC program and provide safe environment for both students and community members.

\section{CONFlicts OF InTEREST Disclosure}

The authors declare no conflicts of interest.

\section{REFERENCES}

[1] Whelton PK, Carey RM, Aronow WS, et al. 2017 ACC/AHA/AAPA/ABC/ACPM/AGS/APhA/ASH/ASPC/NMA/PCNA guideline for the prevention, detection, evaluation, and management of high blood pressure in adults. J Am Coll Cardiol. 2018; 71(19): e248. PMid:29146535. https://doi.org/10.1016/j.jacc.2017.11.006

[2] Correction to: Heart disease and stroke statistics-2018 update: A 
report from the American Heart Association. Circulation. 2018; 137(12): e493. https://doi.org/10.1161/CIR.0000000000 000573

[3] Butler county community health assessment 2017. 2017.

[4] Kim K, Choi JS, Choi E, et al. Effects of community-based health worker interventions to improve chronic disease management and care among vulnerable populations: A systematic review. Am J Public Health. 2016; 106(4): e28. PMid:26890177. https://doi.or g/10.2105/AJPH. 2015.302987

[5] Glynn LG, Murphy AW, Smith SM, et al. Interventions used to improve control of blood pressure in patients with hypertension. Cochrane Database Syst Rev. 2010; (3): CD005182. PMid:20238338. https://doi.org/10.1002/14651858.CD005182.pub4

[6] Aycock DM, Kirkendoll KD, Gordon PM. Hypertension education and screening in african american churches. J Community Health Nurs. 2013; 30(1): 16-27. PMid:23384064. https : //doi .org/10 $.1080 / 07370016.2013 .750197$

[7] Dodani S, Beayler I, Lewis J, et al. HEALS hypertension control program: Training church members as program leaders. Open Cardiovasc Med J. 2014; 8: 121-127. PMid:25685245. https: //doi.org/10.2174/1874192401408010121

[8] Dye CJ, Williams JE, Evatt JH. Improving hypertension selfmanagement with community health coaches. Health Promot Pract. 2015; 16(2): 271-281. PMid:24837989. https ://doi .org/10.1 $177 / 1524839914533797$

[9] Victor RG, Ravenell JE, Freeman A, et al. A barber-based intervention for hypertension in African American men: Design of a group randomized trial. Am Heart J. 2009; 157(1): 30-36. PMid:19081393. https://doi.org/10.1016/j.ahj.2008.08.018

[10] Zoellner J, Connell C, Madson MB, et al. HUB city steps: A 6-month lifestyle intervention improves blood pressure among a primarily african-american community. J Acad Nutr Diet. 2014; 114(4): 603 612. PMid:24534602. https://doi.org/10.1016/j.jand. 201 3.11 .020

[11] AHA. Check.change.control.toolkit for implementation. Available from: https ://www.heart.org/-/media/data-import/down loadables/check-change-control-implementation-too 1kit-ucm_473905.pdf. Updated 2019. Accessed 07/2019.
[12] Thomas KL, Shah BR, Elliot-Bynum S, et al. Check it, change it: A community-based, multifaceted intervention to improve blood pressure control. Circ Cardiovasc Qual Outcomes. 2014; 7(6): 828-834. PMid:25351480. https://doi.org/10.1161/CIRCOUTCOMES. 1 14.001039

[13] Anderson ML, Peragallo Urrutia R, O'Brien EC, et al. Outcomes of a multi-community hypertension implementation study: The american heart association's check. change. control. program. J Clin Hypertens (Greenwich). 2017; 19(5): 479-487. PMid:28058813. https ://doi.org/10.1111/jch.12950

[14] Anderson ML, Peragallo Urrutia R, O'Brien EC, et al. Outcomes of a multi-community hypertension implementation study: The american heart association's check. change. control. program. The Journal of Clinical Hypertension. 2017; 19(5): 479-487. PMid:28058813. https://doi .org/10.1111/jch. 12950

[15] Krumwiede KA, Van Gelderen SA, Krumwiede NK. Academichospital partnership: Conducting a community health needs assessment as a service learning project. Public Health Nurs. 2015; 32(4): 359-367. PMid:25307990. https://doi .org/10.1111/phn. 12 159

[16] Salerno JP, McEwing E, Matsuda Y, et al. Evaluation of a nursing student health fair program: Meeting curricular standards and improving community members' health. Public Health Nurs. 2018; 35(5): 450457. PMid:29667239. https://doi.org/10.1111/phn. 12402

[17] Flinders BA, Nicholson L, Carlascio A, et al. The partnership model for service-learning programs: A step-by-step approach. American Journal of Health Sciences. 2013; 4(2): 67. https : //doi .org/10 $.19030 /$ ajhs.v4i2.7760

[18] Flinders BA, Gilb K, Neu T. Teenage pregnancy and sexually transmitted infection prevention: A pilot study exploring knowledge and reported behaviors. American Journal of Health Sciences (AJHS). 2014; 5(2): 53-94. https://doi.org/10.19030/ajhs.v5i2.8 992

[19] AHA. 4 month HBP educational series. Available from: https: //www.heart.org/-/media/data-import/downloadable s/ccc-4-month-educational-series-ucm_489642.pdf. Updated 2018. Accessed 07/2019. 